\title{
INEJECUTABILIDAD DE UN LAUDO ARBITRAL COMERCIAL INTERNACIONAL ANULADO POR UN ESTADO SEDE: ESTADO DE LA CUESTIÓN EN CHILE
}

\author{
María Fernanda VÁSQUEZ PALMA*
}

\section{1) ANTECEDENTES DE LA SENTENCIA ${ }^{1}$}

Internacional Sociedad Energética Francesa S.A. (EDFI), por medio de sus representantes, presentó ante la Corte Suprema de Chile una Solicitud de reconocimiento y ejecución de un laudo arbitral dictado con fecha 22 de octubre de 2007, en Buenos Aires, República Argentina, por el Tribunal Arbitral constituido conforme al Reglamento de Arbitraje de la Cámara de Comercio Internacional (CCI), integrado por los jueces árbitros Jean Paul Beraudo; Rafael Illescas Ortiz, y Henri Álvarez, en el arbitraje CCI. El caso se singularizó bajo el no 1231/KGA/CCO/JRF, donde obró como actora la sociedad EDFI y como demandadas ENDESA INTERNACIONAL SA, constituida según las leyes de Espańa, domiciliada en Madrid, y la sociedad YPF, constituida según las leyes de la República de Argentina, con domicilio en Buenos Aires.

La sentencia que se pretendía ejecutar en Chile había acogido parcialmente la demanda de EDFI en contra de ENDESA y de YPF, resolviendo que ENDESA debía pagarle a la primera la suma de US\$ 147.000.000 y la sociedad YPF la suma de US\$40.000.000. Por otra parte, también acogió la demanda reconvencional de ENDESA en el sentido de que EDFI debía pagarle a ENDESA US\$46.242.125, y a YPF US\$11.056.150, determinando en ambos casos la compensación de los créditos respectivos. Las sumas por las que se solicita el exequátur corresponden a los créditos resultantes a favor de EDFI luego de aplicada la compensación, y se invoca para ello el hecho que tanto ENDESA como YPF tienen importantes activos en Chile.

La solicitante plantea que el laudo arbitral, cuyo exequátur se solicita, tiene el carácter final, definitivo y vinculante, y enfatiza que en razón de su obligatoriedad e imperatividad de que aparece revestido, las partes se hallan en la necesidad de darle cumplimiento. Hace presente que en noviembre de 2007, todas las partes interpusieron recursos de nulidad en

\footnotetext{
* Doctora en Derecho, Universidad Complutense de Madrid (España). Magíster en Derecho privado. Profesora de Derecho Comercial y Derecho Internacional Privado, Facultad de Ciencias Jurídicas y Sociales. Universidad de Talca. Correo electrónico: mfvasquez@utalca.cl Cita: MJCH_MJJ29225 | ROL: 4390-10, MJJ29225. Disponible en www.microjuris.cl
} 
contra del mencionado laudo con sujeción al procedimiento vigente en la sede de arbitraje, Buenos Aires, ante la Cámara de Apelaciones en lo Comercial de dicha ciudad, la cual dictó sentencia acogiendo la solicitud de nulidad planteada tanto por EDFI, como por ENDESA e YPF. En vista de ello, puntualizan que EDFI dedujo recurso extraordinario de apelación para ante la Corte Suprema de Justicia de la Nación Argentina, solicitando que se revocara la decisión anterior, recurso que fue declarado inadmisible por dicho tribunal por resolución de 9 de marzo de 2010. Empero EDFI interpuso con fecha 30 de mismo mes un recurso de queja ante el seńalado Tribunal para que se dejara sin efecto la decisión anterior, el que a la fecha de esta presentación se encontraría aún pendiente.

A pesar de lo anterior, enfatiza el hecho que ni las referidas acciones de nulidad, ni la sentencia de la Cámara impiden ejecutar el laudo arbitral, de hecho, se ha instado por el cumplimiento de este laudo habiéndose concedido el exequátur en Francia, en marzo de 2008 por el Tribunal de Grande Instance de París para ser cumplido en dicho país. Afirma que la existencia de un fallo pronunciado por un tribunal del país sede del arbitraje, que declara la nulidad del laudo, no se opone a la obligatoriedad de este, pues el recurso de nulidad no permite una revisión del fondo de lo fallado por el tribunal arbitral, defecto en que se habría incurrido al pronunciarse sobre la nulidad del laudo en Argentina.

Las contrarias (ENDESA Latinoamericana SA e YPF SA), solicitan se rechace íntegramente la solicitud de exequátur interpuesta por EDFI, denegando toda eficacia a la sentencia arbitral extranjera cuyo reconocimiento en Chile se pretende obtener, dado que dicho fallo no existe jurídicamente por haber sido anulado completamente por el tribunal argentino con competencia y jurisdicción en la materia. Agregan que la aludida nulidad se encuentra ejecutoriada en conformidad a las leyes argentinas, ya que con fecha 29 de junio de 2010, la Corte Suprema de Argentina desestimó la queja interpuesta por EDFI, de modo que en la actualidad no existen recursos pendientes en contra del mencionado fallo. De este modo, la sentencia arbitral sobre la que se solicita exequátur carece por completo de eficacia jurídica que permita su reconocimiento y ejecución. Por otra parte, agrega que la peticionaria no satisfizo la carga probatoria que le impone el artículo 246 del CPC en orden a acompańar un certificado de la Cámara de Apelaciones en lo Comercial de Buenos Aires, en que conste la autenticidad del laudo. Adicionalmente esgrime que la solicitante vulnera el principio de los actos propios, ya que ella misma dedujo en su momento uno de los recursos de nulidad del laudo arbitral, no resultando consecuente ahora que pretenda desconocer los efectos de esa conducta. Plantea que la Corte Suprema para conocer del exequátur tiene una limitación territorial desde que tratándose de una sentencia dictada en el extranjero debe existir vinculación entre las partes del exequátur 
que se trata de obtener y la jurisdicción de los tribunales nacionales; tal requisito no existiría en la especie en tanto las partes involucradas tienen su domicilio fuera de Chile, por lo que no existe un factor de conexión. La existencia de bienes en el territorio nacional sería en su opinión insuficiente para ello.

La Fiscal de la Corte Suprema fue de la opinión de rechazar el exequátur en base a los siguientes fundamentos: a) El documento acompañado a estos efectos no estaría debidamente legalizado, por lo que no cumpliría los requisitos normativos establecidos a estos efectos; b) La Corte Suprema carece de jurisdicción para conocer de la solicitud materia de estos autos de conformidad a lo dispuesto en el art. 251 del CPC, en relación con el art. 76 de la Constitución Política; y c) El laudo arbitral cuyo exequátur se impetra no tendría fuerza obligatoria, pues habría sido anulado por la Cámara Nacional de Apelaciones en lo Comercial de Buenos Aires, donde fue dictado.

Finalmente, el máximo Tribunal resolvió rechazar la solicitud de exequátur argumentando fundamentalmente que establecida con claridad la condición de nulo que ostenta el laudo arbitral de que se trata, ha de tenerse con ello por configurada, de acuerdo con lo que se previene en la normativa que se acaba de examinar, una causal específica prevista en ella para la denegación de la fuerza obligatoria de dicho fallo en nuestro país. Agrega que no puede pasar desapercibida la circunstancia de haber EDFI instado ante los tribunales ordinarios superiores de la República Argentina por la nulidad del fallo, resultando, por lo tanto, carente de coherencia que, una vez declarada dicha nulidad, pretenda que se le reconozca en Chile fuerza obligatoria a esa misma sentencia que a causa de la nulidad ha quedado desprovista de eficacia jurídica en el propio país donde fue pronunciada. Esta situación, en opinión de la Excma. Corte, repugnaría al principio de los actos propios, con amplia consagración en la doctrina y la jurisprudencia. Señala que el hecho que el Tribunal de Grande Instance de París hubiera otorgado el exequátur para que el laudo arbitral en comento se cumpliera en Francia, en nada priva de fuerza a los razonamientos aducidos precedentemente, y por otra parte, esta decisión habría sido anterior a que los tribunales dejaran a firme la nulidad antedicha.

\section{2) ANÁLISIS Y REFLEXIONES QUE SURGEN DEL FALLO}

\section{1) LAS AFIRMACIONES, LO NEBUlOSO Y LO PENDIENTE DE LA SEN- TENCIA}

A pesar de las extensas alegaciones realizadas por las partes en este juicio, la Excma. Corte Suprema resuelve tomando en consideración solo algunos de los puntos en conflictos, que son a saber los siguientes: 
A. La Excma. Corte dedica los primeros considerandos a recordar cuestiones generales sobre el reconocimiento y ejecución de las sentencias extranjeras en Chile, para finalmente concluir que ello es posible de acuerdo a la doctrina y la normativa imperante.

B. A partir de ello el sentenciador se detiene latamente en discernir cuál es la legislación aplicable en este exequátur. Este análisis parece un esfuerzo innecesario pues con relativa facilidad se pudo advertir que el caso debía regirse por los tratados vigentes en Chile y que son: a) La Convención de Nueva York de 1958 sobre Reconocimiento y la Ejecución de las Sentencias Arbitrales Extranjeras promulgada por el Decreto Supremo $\mathrm{N}^{\circ} 664$ del Ministerio de Relaciones Exteriores, publicado en el Diario Oficial del 30 de octubre de 1975; b) La Convención Interamericana sobre Arbitraje Comercial Internacional suscrita en Panamá en el año 1975; aprobada por el Decreto Ley $\mathrm{N}^{\circ} 1376$, de 1973; publicada en el Diario Oficial de 12 de julio de 1976; y c) El Acuerdo de Cooperación y Asistencia Jurisdiccional en Materia Civil, Comercial, Laboral y Administrativa entre los Estados Parte del Mercosur y las Repúblicas de Bolivia y Chile, suscrito el 5 de julio de 2002; aprobado por el Congreso Nacional el 30 de septiembre de 2008; y promulgado por Decreto Supremo $N^{\circ} 71$ de 24 de abril de 2009, publicado en el Diario Oficial del 7 de agosto del mismo ańo. A ellas deben ańadirse la Ley $\mathrm{N}^{\circ} 19.971$ sobre Arbitraje Comercial Internacional, publicada en el Diario Oficial de 29 de septiembre de 2004, cuyas normas en los aspectos concernientes al reconocimiento y ejecución de dichos fallos, se hacen también extensivas a aquellos pronunciados en otro país (artículos 35 y 36).

C. En relación al cuestionamiento relativo a la autenticidad del laudo arbitral, bajo el fundamento que este no constaba en la forma prescrita por el art. 246 del CPC, aquel se desestima por haber sido pronunciado el fallo por un tribunal arbitral adscrito a la Corte Internacional de París, circunstancia que permite reconocerle al Secretario de la Corte Internacional de Arbitraje la condición de ministro de fe idóneo para certificar la autenticidad del laudo. Agrega que las propias demandadas en este juicio de exequátur acompańaron al expediente copia legalizada de la sentencia expedida por la Cámara de Apelaciones en lo Comercial de Buenos Aires, Argentina, que declaró la nulidad del laudo, hecho que corrobora su autenticidad.

Hasta aquí (considerando décimo de la sentencia) podemos advertir la resolución de cuestiones obvias que no requerían este grado de atención, sobre todo si se considera que no se trata de la primera vez que en Chile se pide el exequátur de una sentencia arbitral extranjera, por lo que existe suficiente doctrina jurisprudencial en la materia que no ameritaba este grado de detención por parte del juzgador. 
Por otra parte, se incurre en una inconsistencia pues habiendo resuelto previamente que procedía aplicar la LACI y los tratados internacionales en la materia, no las normas del CPC, luego la Corte vuelve a preguntarse por la validez y autenticidad del laudo en atención a lo dispuesto en el art. 246 de este último cuerpo legal. Bastaba, entonces, con remitirse a lo señalado precedentemente en relación a la ley aplicable.

D. Los restantes considerandos se dedican a resolver las alegaciones de fondo vertidas por las partes, aunque no en forma completa. El sentenciador, luego de hacer una relación de eventos y fechas, dispone que "establecida con fehacencia la condición de nulo que ostenta el laudo arbitral de que se trata, ha de tenerse con ello por configurada de acuerdo con la normativa que se acaba de examinar, una causal especifica prevista en ella para la denegación de fuerza obligatoria a dicho fallo en nuestro pais". Este es el punto más débil del fallo pues la Excma. Corte asume incorrectamente que la nulidad del laudo provoca su inejecución. Esto es erróneo en tanto el Art. V de la CNY dispone que se "Podrá" denegar el reconocimiento y la ejecución de la sentencia -norma que copia el art. 36 de la LMU y la LACI en Chile- ${ }^{2}$, con lo que se cambia el paradigma precedente de la Convención de Ginebra y se establece la posibilidad de abolir el doble exequátur que en la práctica se puede llevar a cabo. En este sentido, la nulidad del laudo no es en sí misma un obstáculo para denegar la ejecución del mismo. Se faculta al juez para denegar y, por tanto, también para ejecutar el fallo, de manera que el sentenciador no pudo seńalar con tanta soltura que el hecho de la nulidad provocaba irremediablemente la inejecución del fallo arbitral.

Dicha causal constituye, por lo demás, hoy en día el aspecto más polémico en materia de reconocimiento de las sentencias extranjeras, a la luz de las decisiones de los tribunales franceses y estadounidenses, los que en casos similares han reconocido las sentencias anuladas en el país de su sede según pasamos en el siguiente apartado de manera detallada ${ }^{3}$. Esta doctrina referida a las problemáticas que subyacen a este conflicto jurídico se encuentra suficientemente discutida en Derecho comparado ${ }^{4}$. Un correcto y completo análisis de la situación discutida en esta causa debiera haber considerado justamente tales antecedentes. En tal sentido, la Corte pudo haber resuelto que no obstante haberse decretado la nulidad del

2 De hecho el art. 36 inc. final de la LACI, dispone que: "2) Si se ha pedido a un tribunal de los previstos en el inciso v) del apartado a) del párrafo 1) del presente artículo la nulidad o suspensión del laudo, el tribunal al que se pide el reconocimiento o la ejecución podrá, si lo considera procedente, aplazar su decisión y, a instancia de la parte que pida el reconocimiento o la ejecución del laudo, podrá también ordenar a la otra parte que dé garantias apropiadas".

3 Mereminskaya, E (2007), "Arbitraje comercial internacional", en Mario Ramírez Necochea: Análisis crítico del Derecho internacional privado chileno, LexisNexis, p. 148.

4 Vásquez palma, M. F. (2011), "Relevancia de la sede arbitral y criterios que determina su elección”, Revista Chilena de Derecho Privado, No16, pp. 75-134. 
laudo, esta podía ejecutarse de todas maneras en Chile, sin embargo, este análisis no se llevó a cabo.

E. Por otra parte, el sentenciador estimó que el hecho de haber la demandante deducido recurso de nulidad en la materia no le autorizaba luego a demandar la ejecución del laudo, pues ello -además de ser incoherente- repugnaría el principio de los actos propios (venire contra factum propium non potest). Esta es una afirmación delicada de sostener si se considera que el recurso de nulidad es normalmente el único recurso del que disponen las partes en contra del laudo arbitral, y este puede interponerse en contra de toda la sentencia o de una parte de ella. Entonces, si pensamos en que los contradictores no pueden interponer el recurso de nulidad pues si lo hacen, quedarían desprovistos de la posibilidad de ejecutar el laudo con posterioridad, ello equivaldría a eliminar -en la práctica- un legítimo derecho de las partes, pues estas no recurrirían por el temor de luego no poder ejecutar el fallo. El contrasentido es aún más notable si se considera que en el caso de autos se solicitó la nulidad parcial del fallo, que era aquella que afecta a los intereses de la demandante, lo propio hizo la demandada y por ello el fallo quedó luego íntegramente anulado. En otras palabras, aquí no pudo esgrimirse la aplicación de esta doctrina tanto desde una óptica general, como particular.

F. Finalizando el fallo la Excma. Corte seńala que las reflexiones precedentes conducen necesariamente a desestimar la solicitud del exequátur presentada por EDFI, sin necesidad de incursionar en el análisis de otras argumentaciones desarrolladas por las partes en este procedimiento. Con ello, deja de pronunciarse sobre varias cuestiones legadas por las partes, entre las que destaca la competencia de la Corte Suprema para conocer de este exequátur, es decir, la vinculación efectiva que tenía Chile para que el fallo arbitral fuere ejecutado en su territorio, tema en el que no se advierte una mayor profundización por el sentenciador y que debió -en base a su innegable importancia- ser revisada en el fallo.

\section{2) TEMAS EN CONFLICTO SUBYACENTES Y POSTURA QUE SE RECOGE EN LA SENTENCIA}

\subsection{1) Exposición del conflicto en Derecho comparado}

Esta sentencia es la primera que se pronuncia respecto de una materia que ha despertado gran interés en la doctrina arbitral en estos últimos años, de allí su relevancia En general, la discusión en Derecho comparado se ha centrado en dos posiciones antagónicas entre sí que ponen en jaque la importancia real que posee el Estado sede en un arbitraje comercial internacional, esto es, la tesis de la deslocalización y la tesis de la localización. Nos referiremos a ella a continuación -en combinación con los 
antecedentes de este juicio- en el convencimiento que este era uno de los puntos neurálgicos del caso al que no se prestó mayor atención.

La tesis de la deslocalización ha instaurando lentamente la disminución de la relevancia del Estado sede basándose primordialmente en la Convención de Nueva York, en adelante CNY (Art. VI), y la Ley Modelo de la Comisión de las Naciones Unidas para el Derecho Mercantil Internacional, en adelante LMU UNCITRAL (Art. 36 No1), que permiten la ejecución de la sentencia arbitral a pesar de la petición de nulidad del laudo en el Estado sede ${ }^{5}$; a ello se agrega que varios países se han fundado en el Art. VII de la CNY para hacer prevalecer su derecho interno sobre el texto internacional a fin de ejecutar laudos anulados por los tribunales del lugar de la sede arbitral ${ }^{6}$; y el hecho que las causales para rechazar la ejecución de un laudo son normalmente las mismas que las establecidas para anular una sentencia arbitral, de manera que no se justificaría un doble control ${ }^{7}$. En este sentido, se esgrime la pérdida de relevancia del recurso de nulidad que incluso es posible renunciar anticipadamente en ciertas legislaciones. La segunda tesis desconoce parte de lo antes expresado y afirma, en cambio, que dicha elección entraña efectos relevantes asociados principalmente a la validez del laudo arbitral y con ello la viabilidad del

5 La Convención afirma que si se ha pedido a la jurisdicción de la sede del arbitraje la anulación o la suspensión de la sentencia, la autoridad judicial ante la cual se invoca dicha sentencia "podrá", si lo considera procedente, aplazar la decisión sobre la ejecución de la sentencia. A este respecto, cabe seńalar que el proyecto inicial de la CNY, preparado por la Cámara de Comercio Internacional (CCI), hacía referencia al laudo internacional y no extranjero, de manera que los redactores propugnaban por un arbitraje verdaderamente internacional y deslocalizado, sin un nexo particular con un ordenamiento jurídico nacional. Fue con posterioridad, y ante la reticencia de ciertos países influenciados por la lex arbitri y la sede arbitral, que los redactores optaron por la versión que actualmente impera; no obstante ello y la referencia al lugar del arbitraje, el texto mismo de la CNY permite reconocer el carácter visionario de sus redactores. Sobre el tema, véase entre otros: Convención sobre reconocimiento y la ejecución de sentencias arbitrales extranjeras, Nueva York, (1958), de la comisión de las naciones unidas para el derecho mercantil internacional, CNUDMI: http:www.uncitral.org/uncitral_texts/arbitration/nyconvention. html; Mantilla-Serrano, Fernando (2009). "Algunos apuntes sobre la ejecución de los laudos anulados y la Convención de Nueva York", 15 International Law, Rev. Colombiana de Derecho Internacional, pp. 15-40; Pérez Nieto, Leonel \& Graham, James (2006). "La muerte programada del Estado sede del arbitraje", Rev. Latinoamericana de Mediación y Arbitraje, N² 2, México, pp. 197-208; Berg, Albert Jan Van Den (2008). "La aplicación de la Convención de Nueva York de 1958 a laudos no nacionales", en Tawil, G. \& Zuleta, E., (Coords.): El arbitraje comercial internacional. Estudio de la convención de Nueva York con motivo de su 50ªniversario, Buenos Aires: Abeledo-Perrot, pp. 100 y ss.

6 Este precepto seńala: "Las disposiciones de la presente Convención no afectarán la validez de los acuerdos multilaterales o bilaterales relativos al reconocimiento y la ejecución de las sentencias arbitrales concertados por los Estados contratantes ni privarán a ninguna de las partes interesadas de cualquier derecho que pudiera tener a hacer valer una sentencia arbitral en la forma y medida admitida por la legislación o los tratados del país donde dicha sentencia se invoque". 
laudo en el contexto internacional, pues la nulidad del mismo presenta efectos expansivos que impiden su ejecución.

En lo medular, se trata de un tema controvertido y muy relevante en la actualidad, pues detrás de él subyacen claramente dos concepciones filosóficas del instituto arbitral bien diferenciadas: la primera tiene un sello claramente universalista, donde la sede no es más que un parámetro en medio de muchos otros ${ }^{8}$; mientras que la segunda presenta un corte territorialista al considerar que la sede es un elemento esencial en el arbitraje?

En detalle, la tesis de la deslocalización pone acento en el principio de autonomía ${ }^{10}$ (arbitration unbound), y ha sido la jurisprudencia francesa su máxima impulsora ${ }^{11}$. La virtud de ella puede resumirse en haber generado debates muy interesantes en relación al arbitraje, que han traspasado el confortable plano de las ideas, para plasmarse en ciertas sentencias judiciales que en definitiva han relativizado la importancia concreta del lugar del arbitraje ${ }^{12}$, abogando por el carácter transnacional del laudo en sintonía con los principios que impregnan al instituto arbitral ${ }^{13}$.

Se funda, además de lo ya relatado, en tres argumentos relacionados entre sí. El primero dice relación con la pérdida de relevancia del sistema

Para Clay esta disyuntiva encuentra su base en el diferente origen cultural e intelectual de sus autores. CLAY, Thomas (2007). "La importancia de la sede de arbitraje en el arbitraje internacional: jes todavía relevante?, en Mantilla-Serrano, Fernando (Coord.): Arbitraje internacional. Tensiones actuales, (Ed. Legis, Bogotá), pp., 193-194.

En relación a ello, cabe recordar que una de las primeras filosofías del arbitraje fue propuesta por BATIFFOL, Henri, en aquella época el paradigma reinante era que los árbitros debían aplicar las normas de conflictos de la sede del arbitraje "en tanto lex fori". Fue Goldman el que propuso la idea según la cual los árbitros no tenían foro, y de existir uno, sería el mundo. Asimismo, fue Francescakis (1960) el que señaló que una disciplina tan técnica como el DIPr podía enriquecerse en cuestiones tales como la calificación o el orden público internacional, adoptando concepto universalistas, que estimaba emanados del Derecho natural. Véase: Goldman, Berthold (1963). "Les conflits de loi dans l'arbitrage internacional de droit privé", Recueil des tours, Vol. 109, pp. 347 ss.; Batiffol, Henry (1956). Aspects philosophiques du droit internacional privé, Dalloz, Paris; Gaillard, Emmanuel (2010). Teoría jurídica del arbitraje internacional, Thomson Reuters, Asunción, Paraguay.

Incluso se alude a la multilocalización es decir, la sujeción del laudo a la ley del país en el cual es invocado por diferentes razones que provocan en muchos casos situaciones complejas al no existir unicidad de criterios sobre diversos elementos. Véase Mayer, P. (1984). "L’insertion de la sentence Dans l’ordre juridique francais", Le droit et la practique de l'arbitrage International en France, (Deduci,), pp. 81-84.

11 Para un completo análisis de la injerencia del principio de autonomía en el instituto arbitral, Véase Petsche, M. (2005). The growing Autonomy of International Commercial Arbitration, European Law Publishers, München, pp. 3-4; Fernández Rozas, José Carlos (2005). "El arbitraje comercial internacional entre la autonomía, la anacionalidad y la deslocalización", Rev. Española de Derecho Internacional, Vol. LVII, pp. 605-636; Chatterjeek, C. (2003). "The Reality of the Party Autonomy Rule in International Arbitration", Journal of International Arbitration, vol. 20 No 6, pp. 539-560. En esta línea, Mantilla-Serrano (2009) 19. arbitrage internacional”, Rev. Arb., pp. 326-371. 
conflictualista clásico en el Derecho arbitral que habría cedido hacia la primacía de la regla material ${ }^{14}$, de manera de fijar el resultado sin preocuparse del juego e interacción de reglas de conflicto y puntos de contacto ${ }^{15}$. El Derecho arbitral se deslga así de la Escuela del Derecho internacional privado, pregonando su completa autonomía en la materia.

La segunda advierte la irrelevancia de la sede arbitral en relación a las leyes aplicables, en tanto la sede no tendría más importancia que otros Estados cuyas legislaciones pudieran ser aplicables al arbitraje, a lo que se agrega que el Estado sede no crea lazos sustanciales con la controversia, sino que más bien se trata de un elemento artificial. Esto se debe al hecho que, a diferencia de un arbitraje interno, un árbitro puede tener varios puntos de contacto con legislaciones de más de un país, lo que lleva necesariamente en la búsqueda de las leyes aplicables a cada caso ${ }^{16}$. En tal sentido, debemos recordar que las partes tienen normalmente plena libertad para escoger la legislación o reglas que estimen convenientes para el procedimiento y el fondo del litigio, y estas últimas podrían estar perfectamente desvinculadas a toda ley nacional, como ocurre con la lex mercatoria $^{17}$, de manera que el Estado sede ninguna injerencia debiera tener sobre el particular ${ }^{18}$.

En tercer lugar, se esgrime que el árbitro en un arbitraje comercial internacional no está investido de poder por el Estado en el cual se encuentra la sede y, por tanto, no tiene la obligación de respetar las leyes de policía o de procedimiento de dicho lugar ${ }^{19}$. El arbitraje comercial internacional debe concebirse desnacionalizado, pues no puede sostenerse que el árbitro deba obediencia a ningún orden jurídico estatal, este no tiene lex fori y con ello desaparece la obligación de hacer respetar la ley de un Estado determinado. Su preocupación se circunscribe a velar por el respeto de la voluntad de las partes y de la comunidad internacional, el tribunal arbitral internacional debe resolver un conflicto sobre un territorio, pero no en nombre del Estado que ejerce soberanía sobre dicho territorio.

14 Véase Fouchard, Philips / Gaillard, Emmanuel / Goldman, Berthold (1999). "On international commercial arbitration” en Gaillards, Emmanuel y SAVAGE, John (eds): On International commercial arbitration, La Haya: Kluwer Law International, p. 242.

15 Por ello, Mantilla Serrano se pregunta si es el triunfo del fin sobre el método, o el de la real intención de las partes y del respeto de sus expectativas, sobre construcciones artificiales, locales o coyunturales. Mantilla-Serrano (2009) 239.

16 Sobre la defensa del arbitraje transnacional, Véase: Oppetit, Bruno (2006). Teoría del arbitraje, Legis, pp. 192-195.

17 Véase Art. 28 LMU.

18 Esta desvinculación del contrato y del arbitraje puede ser progresiva, las partes pueden elegir reglas que no tengan un origen estatal para gobernar sus relaciones, por ejemplo, la lex mercatoria, o la aplicación de los principios generales del Derecho, o comunes (pacta sunt servanda, fuerza mayor, rebuc sic stantibus, el principio rector de la buena fe en las relaciones comerciales, respeto a los derechos adquiridos, el de equidad, etc.). 
A partir de ello, si los árbitros no tienen fuero, los laudos tampoco tienen nacionalidad, por lo que en realidad el laudo flota hasta su ejecución, y no es posible atribuir al mismo ninguna conexión con un derecho nacional ${ }^{20}$. En este entendido, el laudo no es más que un acto privado como lo es un contrato ${ }^{21}$, de manera tal que únicamente habría de recurrirse a las cláusulas contractuales y al propio criterio del tribunal arbitral. Como corolario de ello algunas legislaciones han permitido la renuncia del recurso de nulidad por voluntad de las partes ${ }^{22}$, o la posibilidad de acudir a un tribunal distinto al de la sede arbitral ${ }^{23}$.

De la mano de lo anterior se argumenta finalmente, que si bien antes un laudo anulado por un Estado sede impedía su ejecución por otro Estado, actualmente tal afirmación ha perdido efectividad en la práctica, a partir de las sentencias pronunciadas en dicho sentido. El primer caso que plasmó esta tesis data de principios de los ańos 80 , conocido como "Societé Palback Ticaret c. Société Norsolor" 24 . La Corte de Casación francesa reconoció la validez del laudo proferido en Austria, y anulado a su vez por las cortes austriacas, y sostuvo, con base en el Art. VII de la CNY, que un juez no puede apoyarse en esa Convención para denegar el reconocimiento y ejecución de un laudo cuando su derecho nacional permita considerar ese laudo como válido y susceptible de ejecución. En opinión de la Corte corresponde al juez francés de la ejecución "...investigar, inclusive de oficio, si el derecho francés no permite a la parte que se ve beneficiada por el laudo, el derecho a prevalerse del mismo". Otra decisión similar proferida igualmente por la $1^{\circ}$ Sala de la Corte de Casación de París, ocurrió en la causa Société Polish Ocean Line v. Société Jolasry ${ }^{25}$, que consideró que la suspensión o anulación del laudo en su país de origen, si bien

20 Sobre el tema, véase, entre otros: PAulsson, J. (1983). "Delocalization of International Commercial Arbitration: When and Why It Matters", International and Comparative Law Quarterly, No 33, pp. 53-61. SAntos Belandro, R. (2004). "Se ha instalado un provechoso quid quo en los Estados Latinoamericanos respecto del arbitraje”, Rev. Vasca de Derecho Procesal y Arbitraje, tomo XVI, Bilbao, Mayo, pp. 28-38; Fernández Rozas, José Carlos (2008). Tratado de arbitraje comercial en América Latina, Madrid: Iustel, pp. 1190 - 1195. Véase Graham, James (2001). "Grundlegung y lex contractus en los contratos estatales", Rev. Latinoamericana de Mediación y Arbitraje, No18.

22 Las normativas de Francia y Suiza se inscriben en esta dirección.

23 Véase Graham, James (2001). "La deslocalización del arbitraje virtual”, Rev. De Derecho Informático, No40, nov. Disponible en: http://www.alfa-redi.org/rdi-articulo.shtml?x=879

24 Esta Corte seńaló: “(...)El juez francés no puede denegar la ejecución, cuando el laudo ha sido anulado o suspendido por una autoridad competente del pais en el cual ha sido rendido, con base en una causal que no forma parte de las enumeradas en el Art. 1502 NCPC, aun cuando esté prevista por el Art. V.. 1, e de la CNY (...)". Corte de Casación de París, sección 1a Civil, 9 de octubre de 1984. Se puede revisar en: Journal of International Arbitration, 2, 67, XI Yearbook of Commercial Arbitration, YBCA, 484 (1986), 24 International Legal Materials, ILM, 360 (1985); Revue d'Arbitrage, 1983, p. 525; Collection of ICC Arbitral Award 19741985, Kluwer, p. 122.

25 Corte de Casación, Sección Primera Civil (10 de marzo de 1983), Revue de l'Arbitrage, 255 (1993). 
constituía una de las causales previstas por la CNY para poder denegar su reconocimiento y ejecución, también lo era que esta causal no se encontraba dentro de la lista de motivos contemplados en el Art. 1502 del NCPC francés que permite negar el reconocimiento de laudos extranjeros y, por lo tanto, en aplicación del Art. VII de la Convención de Nueva York, la suspensión o anulación del laudo por un tribunal del país donde fue dictado no justifica en sí misma la denegación del reconocimiento y ejecución del laudo en Francia ${ }^{26}$.

Se inscribe en esta línea, aunque con matices diferenciadores en cuanto a los fundamentos esgrimidos, el caso Hilmarton c. OTV ${ }^{27}$. En este la Corte de Casación francesa reconoció la validez de un laudo proferido en Ginebra en el cual el árbitro único había juzgado que el contrato en cuestión -regido por el derecho suizo- violaba el derecho argelino, que prohibía todo tráfico de influencias y sobornos, y atentaba contra el orden público internacional. La Corte ginebrina y el Tribunal Federal suizo anularon el laudo arbitral, pues consideraron que la violación de la ley argelina chocaba con las buenas costumbres establecidas en el derecho suizo, de modo que la decisión del árbitro de anular el contrato constituía una violación evidente del Derecho suizo. La Corte francesa volvió sobre el Art. 1502 del CPC el cual no contemplaba como motivo para denegar el reconocimiento del laudo el hecho que éste se haya anulado en el país de origen, pero fue un poco más allá al declarar expresamente que el laudo dictado en Suiza es un laudo internacional que no se encuentra integrado al sistema jurídico de ese Estado, de manera que el laudo no es contrario al orden público internacional.

Asimismo encontramos la sentencia de la Corte de Apelaciones de París de 2005 en el caso Bechtel ${ }^{8}$, en el este la Corte sostuvo que la exigencia reinvindicada por la DAC (Dirección General de Aviación Civil de Emirato de Dubai) parte perdedora en el arbitraje y que había conseguido la anulación del laudo por la Corte de Dubai bajo el argumento de que habían sido escuchados ciertos testigos sin que estos hubiesen prestado juramento), de agotar todos los recursos legales en el país de origen (del laudo) antes de otorgarle reconocimiento y ejecución en Francia era incompatible con los principios fundamentales del arbitraje de dicho lugar, apoyándose en los artículos 1498 y siguientes del NCPC.

26 Véase Mantilla-Serrano (2009) 230-232.

27 Corte de Casación francesa, 23 de marzo de 1994, "Hilmarton c. Omnium de Traitement et de Valorisation (OTV)". XX Yearboook Commercial Arbitration, YBCA, 663 (1995), Reviue de l'Arbitrage, 994, 327 (1994).

28 Direction Générale de l’Aviation Civile de l’Èmirat de Dubai, DAC v. Société International Bechtel Co. RG 2004/07635. Corte de Apelación de París, Sección Primera Civil, 29 de septiembre de 2005. Véase: Revue de l'Arbitrage, No 695, 2006. 
Bajo estos mismos postulados se guía la sentencia dictada por la Corte de Casación francesa en la causa "Société PT Putrabali Adyamulia c/ société Rena Holding et Société Monguta Est Epices”, de 29 de junio de 2007, conocido como Putrabali29. El laudo arbitral dictado en Londres bajo las reglas del International General Produce Association (IGPA) en el año 2001, fue anulado reabriéndose la discusión. Reenviado la cuestión al tribunal arbitral, este último dictó una nueva decisión favoreciendo a Putrabali. Recurrida la decisión que concedió el exequátur del $1^{\text {er }}$ laudo arbitral, la Corte de Casación francesa sostuvo que el laudo no está integrado en el ordenamiento del país sede, más aún la sentencia arbitral no está ligada a ningún ordenamiento jurídico estatal, pues no tiene nacionalidad. La fuente de su juridicidad es el derecho internacional, cuya regularidad debe ser examinada en el país donde se pide su reconocimiento y ejecución. De este modo, la decisión sobre la validez o invalidez del laudo que haya adoptado el juez local en base al derecho del país sede, no obliga a los jueces de otros países en los cuales ese laudo pretenda ser reconocido y ejecutado ${ }^{30}$. La Corte francesa concedió en este caso el exequátur del laudo anulado por el tribunal inglés argumentando básicamente que la CNY no establece que dicha anulación constituya un obstáculo definitivo a la ejecución; asimismo, esta Convención sienta el principio de la ley más favorable, con lo cual los tribunales franceses pueden invocar que en la ley francesa la anulación del laudo no es una causal de rechazo de ejecución.

Además de las jurisdicciones francesas, otras Cortes también han procedido a ejecutar un laudo anulado, como ocurre con las Cortes Federales de EE.UU. en el caso "Chromalloy Aeroservices v. Fuerza Aérea de la Rep. Árabe de Egipto"31, en el cual el laudo proferido en Egipto y anulado por las Cortes egipcias, por no haber aplicado el derecho administrativo egipcio, fue reconocido como ejecutable bajo la legislación de EE.UU., por la Corte del Distrito de Columbia. La Corte sostuvo que en aplicación del principio de favorabilidad del Art. VII de la CNY el laudo era susceptible de ejecución bajo el "Federal Arbitration Act". Asimismo, la Corte afirmó que no estaba obligada a reconocer el efecto de cosa juzgada a la decisión de anular el laudo de la corte egipcia y precisó que las partes

29 PT Putrabali Adyamulia v. Rena Holding. Nos. 05-18053 y 06-13293, Corte de Casación de París, 29 de junio de 2007. Sobre el tema véase, entre otros: Clay, T., Nota 4, Journal de Droit International, JDI, 1236, 2007; Gaillard, Emmanuel, Nota Société Putrabali Adyamulia c. S.A. Rena Holding et Autre, Revue de l'Arbitrage, 697-720, 2007; MantillaSerrano (2009) 230-232; Rivera, Julio César, (2007), Arbitraje Comercial. Internacional y Doméstico, Lexisnexis, Bs. Aires.

30 En esta sentencia tuvo una enorme relevancia el informe de Jean-Pierre Ancel para la Corte de Casación. Véase: Rivera, Julio César (2007), Arbitraje Comercial. Internacional y Doméstico, Lexisnexis, Bs. Aires.

31 Corte de Distrito de Columbia, 1996. Revue de l'Arbitrage, No,723, 1998. 
habían renunciado a los recursos contra el laudo por lo que no podía la Fuerza Aérea egipcia pretender retractarse de dicho pacto ${ }^{32}$. Las Cortes americanas, sin embargo, a diferencia de la jurisdicción francesa, se han mostrado vacilantes frente a este tema ${ }^{33}$, pues solo algunos ańos después, la Corte de Apelaciones del Segundo Circuito negó el reconocimiento de un laudo dictados y anulados en sus países sedes (Caso Baker Marine ${ }^{34}$ y Martín I. Spier ${ }^{35}$ ). Luego da un nuevo giro en el caso Pertamina ${ }^{36}$, al manifestar que bajo la CNY forma parte de la discreción de Cortes de ejecución ejecutar un laudo independientemente de que haya sido anulado en otro país. Posteriormente, se ha vuelto a cambiar de parecer pues la Corte del Distrito de Columbia, en el caso Termorío ${ }^{37}$, ha negado el reconocimiento del laudo anulado en Colombia por el Consejo de Estado ${ }^{38}$.

Para el sector contrario a esta tesis, constituye una realidad ineludible que el arbitraje debe practicarse en algún lugar ${ }^{39}$ y esta elección supone consecuencias cruciales para el desarrollo del arbitraje y para la propia viabilidad del laudo arbitral, por lo que va mucho más allá de la ubicación física en que se llevará a cabo ${ }^{40}$. Entre los aspectos relevantes destaca la determinación de las normas de base que van a regir la validez de lo actuado por los árbitros, la regulación de las relaciones entre los árbitros y los jueces para conocer las cuestiones relativas al apoyo y control del arbitraje; y en cuanto rige las normas procedimentales ${ }^{41}$. Por otra

33 La Corte sostuvo que en aplicación del principio de favorabilidad del Art. VII de la CNY el laudo era susceptible de ejecución bajo el "Federal Arbitration Act". Asimismo, la Corte afirmó que no estaba obligada a reconocer el efecto de cosa juzgada a la decisión de anular el laudo de la corte egipcia y precisó que las partes habían renunciado a los recursos contra el laudo por lo que no podía la Fuerza Aérea egipcia pretender retractarse de dicho pacto. Baker Marine Ltd. (Nigeria) v. Chevron (Nigeria) Ltd. 191 F. 3d. 194. Corte de Apelaciones para el Segundo Circuito de EEUU, 199.

35 Martin Spier v. Calzaturificio Tecnica SpA. 71 F. 2d. 279. Corte del Distrito Sur de Nueva York, 1999.

36 Karaha Bodas Company, KBC v. Perusahaan Pertambangan Minyak Dan Gas Bumi Negara. Corte de Apelaciones para el Quinto Circuito de EE.UU., 2003.

37 Termorio and Lease Co. V. Electrificadora del Atlático, Electranta. Caso N. 1:03CV025887. Corte Federal del Distrito de Columbia, 17 de marzo de 2007.

38 En una decisión muy cuestionada. Véase: Mantilla-Serrano (2009) 31.

39 Véase Fouchard, Ph. / Gaillard, E. / Goldman, B. (1996). "Traité de l'arbitrage commercial international", Litec No 828.

40 En tal contexto Virgós Soriano, Miguel (2007), "Arbitraje comercial internacional y Convenio de Nueva York de 1958", en diario La Ley, año xxvii, No 6679, Madrid, enfatiza que el CNY 1958 otorga al país de la sede del arbitraje el rol de jurisdicción primaria, lo que implica que el arbitraje se rige en principio por dicha ley y que corresponde a los tribunales de este país la intervención en el proceso arbitral.

41 Sobre el particular, Véase Born, Gary (2010). Internacional Arbitration and Forum Selection Agreements: Drafting and Enforcing, The Netherlands, Country of Publication; Espugles, Carlos, Mota y McNerny, M. reconocían que la libertad de las partes se ve coartada por el reconocimiento de la existencia de una cierta conexión entre el procedimiento arbitral y el lugar donde este tiene lugar. ; Espugles, Carlos, Mota y McNerny, M. 
parte, el lugar del arbitraje determina el Estado en que se considera que el fallo arbitral ha sido dictado, lo que es importante para solicitar su reconocimiento o ejecución en otro Estado. Dicha determinación entraña, además, la consideración de si un arbitraje es nacional o internacional y la arbitrabilidad de una materia ${ }^{42}$.

Se sostiene que la sede no solo provee un escenario material donde se desenvuelve el proceso arbitral, pues no se trata de un asunto de hecho, sino principalmente de contenido, en tanto se brindará un contexto legislativo que puede suplir la voluntad de las partes, si estas nada han expresado sobre un punto concreto, o incluso superponerse a ellas en determinados $\operatorname{casos}^{43}$. En efecto, si bien las partes tendrán un rol activo en la determinación de la ley aplicable ${ }^{44}$, no siempre tal voluntad estará clara o completa, habrá muchos puntos en que el tribunal arbitral deberá considerar en aras de mantener la eficacia del arbitraje y el laudo arbitral ${ }^{45}$. Bajo este postulado se considera que la ley del Estado sede normalmente aplicará sus normas procesales frente a determinados vacíos de la voluntad de las partes, cuya falta podría incluso provocar la nulidad del laudo arbitral $^{46}$. Asimismo, determinará las causales por las que el laudo podrá ser anulado, decisión que tendrá un efecto expansivo, toda vez que -en principio- un laudo anulado no podría ser ejecutado en otro lugar. En esta línea se argumenta que la ejecutabilidad de laudos anulados ha seguido una línea completamente diferente a la antes relatada ${ }^{47}$.

(1986), "Aproximación a la nueva Ley Modelo UNCITRAL sobre arbitraje comercial internacional”, RCEA, Vol. III, Madrid, p. 13.

Véase Fernández Rozas (2008)

Véase Álvarez, Henry (2005). "La escogencia del lugar del arbitraje", Rev. Internacional de arbitraje, No3, Bogotá, Legis, pp. 13-16.

Es lo que se denomina como "normología", Véase Oppetit (2006) 185-186.

Lo escrito acerca del derecho o reglas aplicables por los árbitros internacionales es abundante. Véase, a modo de ejemplo, Grigera Naón, Horacio (2008), "El derecho aplicable en el arbitraje comercial internacional", en El contrato de arbitraje, Bogotá: Ed. Legis, pp. 607-617.

$\mathrm{Si}$ bien ciertas convenciones como la Convención Europea sobre Arbitraje Comercial Internacional (Convención de Ginebra, de 1961) omiten cualquier mención a la aplicación del procedimiento de la sede del arbitraje, nos encontramos con otros casos, como el de la CNY que, respecto al procedimiento a seguir en el arbitraje conserva la referencia subsidiaria al derecho del país sede del arbitraje (Art.V.1, d) que prevé la posibilidad de anular el laudo cuando el procedimiento arbitral no se ha llevado a cabo de conformidad con lo acordado por las partes o, en defecto de ese acuerdo, según lo previsto en la ley del país donde se ha efectuado el arbitraje.

De hecho, solo algunos ańos después de los casos vistos precedentemente, una Corte de los EE.UU. denegó el reconocimiento de los laudos dictados y anulados en Nigeria en el caso Baker Marina en que se desestimó el argumento fundamental de Chrommalloy basado en el artículo VII de la CNY y se concentró exclusivamente en la redacción del convenio arbitral para determinar si este contenía una renuncia a los recursos contra el laudo. Dado que ello no ocurrió de manera expresa, se entendió que las partes se sometían a las consecuencias y vicisitudes propias de haber escogido a Nigeria como lugar de arbitraje, incluida la posibilidad que una Corte nigeriana anulase el laudo. Esta misma situación sucedió en 
Por último, se esgrime que la carencia de foro no implica prescindir por completo de una referencia estatal de una sede arbitral. El procedimiento carente de asistencia judicial produce un grado de inseguridad negativo para el desarrollo de la propia institución. Así también debe reconocerse la posibilidad que existan graves irregularidades en el comportamiento de los árbitros en el desarrollo del procedimiento, formulación de la sentencia y otros hechos que quiebren la igualdad procesal que merecen los litigantes, lo que permitiría el abuso de una de las partes, por ejemplo, en base a su poder económico ${ }^{48}$, de manera que la vinculación a un orden estatal tiene cualidades positivas innegables que deben ser tenidas en cuenta a la hora de tomar la decisión correspondiente.

De lo precedentemente relatado, se puede apreciar que el punto de conflicto radica en la aplicabilidad de la legislación del Estado sede en un arbitraje comercial internacional, cuya piedra angular reside en la formulación del art. 34 de la LMU, que se ha plasmado en la mayor parte de las legislaciones arbitrales modernas, al establecer la posibilidad de aplicar la legislación del Estado sede frente a tres situaciones concretas: Por voluntad de las partes o el árbitro, si así se ha dispuesto; por omisión, esto es, cuando las partes nada han señalado al respecto, caso en que la legislación del Estado sede podrá ser aplicable (Ej. Validez del laudo arbitral); y por imposición, en supuestos que se plantean como relevantes para la legislación de dicho Estado. Sobre este último punto se estable que el laudo podrá ser anulado de oficio si "según la ley del Estado correspondiente, el objeto de la controversia no es susceptible de arbitraje", o si el "laudo es contrario al orden público de ese Estado". La pregunta que surge válidamente entonces es por qué aplicar esta normativa si el Estado sede no es más que un ave de paso en el arbitraje internacional, máxime si se considera que el laudo en cuestión normalmente será ejecutado en otro país que plantea a estos efectos un control análogo respecto del laudo arbitral, ¿cuál es el sentido de esto?, ¿qué se pretende resguardar? Frente a ello no parece ilógico que algunos Estados se planteen la posibilidad de ejecutar el laudo cuando sus propias normas sean más proclives a la validez del mismo, sobre todo si se considera los términos en que fue redactada la CNY.

el caso Martin I. Spier c. Calzaturificio Technica SPA. Este laudo había sido anulado por las cortes italianas en base a que los árbitros habían fundamentado su decisión en una obligación extrańa a la relación contractual sub judice. La Corte del Distrito Sur de Nueva York no reconoció el laudo en tanto ponía en entredicho la seguridad jurídica. Asimismo, el Distrito de Columbia a raíz del caso Termorio negó el reconocimiento de un laudo anulado en Colombia por el Consejo de Estado, y otro tanto aconteció en el caso Bechtel con Aviación Civil de Emirato de Dubai (DCA), cuya sede de arbitraje se encontraba en Dubai.

48 En esta línea, Véase Santos Belandro, Rubén (2004). "Se ha instalado un provechoso quid quo en los Estados Latinoamericanos respecto del arbitraje", Rev. Vasca de Derecho Procesal y Arbitraje, tomo XVI, Bilbao, mayo, pp. 427-433. 


\subsection{2) Aplicación al caso en análisis}

Si el laudo podía ser ejecutado en Chile, a pesar de la declaración de nulidad, era la pregunta ineludible que debían realizarse los sentenciadores considerando que la legislación aplicable posibilita expresamente que pueda suceder. Entonces, la razón del porqué acceder a la ejecución o no era lo más esperado de este fallo para advertir a qué corriente se adscribían los tribunales superiores de justicia chilenos.

Es claro que detrás de esta profusa y compleja discusión se encuentra inmerso el rol del Estado sede en el contexto del arbitraje comercial internacional, el que se vislumbra de manera distinta dependiendo de la filosofía que se abrigue respecto de la institución. Esta realidad nos invita a reflexionar sobre el papel de la sede en el tiempo considerando que aquel puede variar ligado a la tesis que logre predominar sobre el particular ${ }^{49}$. En este punto, podría pensarse que la lógica empleada en la configuración actual sigue la línea interpretativa según la cual la elección de la sede hace presumir la intención de las partes en cuanto a que todo vacío sea llenado o resuelto por la ley del Estado sede, posición compartida por algunos autores como Poudret y Besson ${ }^{50}$, y entendida como el derecho de la sede del arbitraje ${ }^{51}$. Sin embargo, tal tesis es refutada por otro importante sector doctrinal, en el entendido que la elección de la sede arbitral presenta como única certeza que las partes han decidido acudir al arbitraje y no han optado por someter su controversia a tribunal estatal alguno ${ }^{52}$, de manera que nada podría obstaculizar sostener que los vacíos puedan ser llenados por otra normativa, y el orden público y arbitrabilidad a los que se alude en la ley, interpretarse en términos estrictamente internacionales.

49 En tal sentido, hacemos eco de las palabras pronunciadas por Oppetit, en tanto si es verdad que una ideología es un discurso orientado mediante el cual una pasión busca convertirse en un valor, y las pasiones y valores son arbitrarios por no fundarse en la razón, una consecuencia capital se desprende: una ideología no puede ser ni probada, ni refutada; en consecuencia, no es ni verdadera ni falsa, no puede ser otra cosa que eficaz o ineficaz, coherente o incoherente. Opретіт, Bruno (1982). "La notion de source du droit el le droit du comerse internacional", Archives de philosophie du droit. No 27, "Sources" du droit, pp. 43-44.

50 Véase, Poudret, J. y Besson, S. (2007). Comparative Law of Internacional Arbitration, Londres, Sweet \& Maxwell, quienes pesen a no emplear términos como lex arbitri o lex fori, fundan la integralidad del régimen que rige la institución del arbitraje, incluidas la validez formal del convenio arbitral, la arbitrabilidad de la controversia, la composición del tribunal arbitral, las garantías fundamentales del proceso, la asistencia del juez estatal y el control de la regularidad del laudo, en la "loi d'arbitrage" o "lex arbitri", entendida esta como el derecho de la sede del arbitraje.

51 En el mismo sentido, Hirsch, A. (1979). "The Place of Arbitration and the Lex Arbitri", The Arbitration Journal, sep. Vol. 34, no 3, p. 43 que admite que la expresión lex arbitri es equivalente a la lex fori para la aplicación del procedimiento. 
La CNY fijó, hace ya varios años, un criterio mínimo para el reconocimiento y ejecución de laudos arbitrales; pero, al mismo tiempo, dejó la puerta abierta para que aquellos países que así lo consideraran pudieran, no obstante esos criterios mínimos, ir más allá y reconocer y ejecutar laudos a los que, de otra forma, podría rehusárseles la ejecución por caer bajo los criterios previstos por la Convención. En esta línea, las razones que justifican la declaración de nulidad y los jueces que llegan a ella resultan cruciales para determinar los efectos expansivos y extraterritoriales de dicha decisión por otro Estado. Adicionalmente debemos considerar que las decisiones judiciales no tienen aplicación extraterritorial. Si por alguna razón se considera que la decisión de anular el laudo, dictada por el juez competente para conocer de la anulación, se impone a todos los demás países e impide el reconocimiento y ejecución del laudo así anulado, de igual forma debería entonces reconocérsele un valor extraterritorial a la decisión de no anular; sin embargo, ningún país está preparado para aceptar que un tercer país decida sobre la ejecución de la que gozará un laudo extranjero en su territorio. En consecuencia, es posible que el mal menor siga siendo aquella solución que permite la convivencia entre países cuyos criterios de nulidad no responden a los estándares internacionales y aquellos que desean reconocer al arbitraje internacional un verdadero estatuto de ordenamiento jurídico autónomo. La Convención permite ambas posibilidades ${ }^{53}$.

Dado que este análisis no se llevó a cabo en el presente juicio por la Excma. Corte Suprema, debo concluir que su correcta resolución está aún pendiente.

\section{BIBLIOGRAFÍA}

- Álvarez, Henry (2005). "La escogencia del lugar del arbitraje”, Rev. Internacional de arbitraje, No 3, Bogotá, Legis, pp. 13-16.

53 En Holanda, mediante decisión de 28 de abril de 2009, la Corte de Apelaciones de Ámsterdam, aplicando la Convención, concedió el exequátur a cuatro laudos que habían sido anulados por los tribunales competentes en Rusia. Aunque la principal razón para no tener en cuenta la decisión rusa de anular los laudos fue haber considerado como demostrado que las decisiones de anulación fueron proferidas por un tribunal parcial y falto de independencia, la Corte de Apelaciones hizo dos manifestaciones importantes. En primer lugar, dejó sentado que la Convención se refiere exclusivamente al reconocimiento y ejecución de laudos arbitrales y no a las decisiones judiciales de anulación de dichos laudos. En segundo lugar, la Corte de Ámsterdam expresa claramente que nada en la Convención obliga a los tribunales holandeses de exequátur a reconocer, sin más, las decisiones del juez de la anulación. Al no existir pronunciamiento sobre este punto, la duda se mantiene y obliga a tener presente estos antecedentes de una forma más clara y coherente en orden a satisfacer esta y otras inquietudes en el futuro. Véase: Mantilla Serrano (2009) 35. 
- Batiffol, Henry (1956). Aspects philosophiques du droit internacional privé, Paris: Dalloz.

- Berg, albert jan van den (2008). "La aplicación de la Convención de Nueva York de 1958 a laudos no nacionales”, en TAwIL, G. \& Zuleta, E., (Coords.): El arbitraje comercial internacional. estudio de la convención de nueva york con motivo de su $50^{\circ}$ aniversario, Buenos Aires: Abeledo-Perrot.

- Born, Gary (2010). Internacional Arbitration and Forum Selection Agreements: Drafting and Enforcing, The Netherlands, Country of Publication.

- Chatterjeer, C. (2003). "The Reality of the Party Autonomy Rule in International Arbitration", Journal of International Arbitration, vol. 20 No6, Deciembre, pp. 539-560.

- Clay, Thomas (2007). "La importancia de la sede de arbitraje en el arbitraje internacional: ¿es todavía relevante?, en Mantilla-SERrano, Fernando (Coord.): Arbitraje internacional. Tensiones actuales, Bogotá: Ed. Legis.

- Espugles, Carlos, Mota y McNerny, M. (1986), "Aproximación a la nueva Ley Modelo UNCITRAL sobre arbitraje comercial internacional", $R C E A$, Vol. III, Madrid, p. 13.

- Fernández Rozas, José Carlos (2005). "El arbitraje comercial internacional entre la autonomía, la anacionalidad y la deslocalización”, Rev. Española de Derecho Internacional, Vol. LVII, pp. 605-636.

(2008). Tratado de arbitraje comercial en América Latina, Madrid, Iustel, pp. 1190 - 1195. Fouchard, Ph. / Gaillard, E. / Goldman, B. (1996), "Traité de l'arbitrage commercial international”, Litec No 828.

- Gaillard, Emmanuel (2010). Teoría jurídica del arbitraje internacional, Asunción, Paraguay: Thomson Reuters.

- MaYer, P. (1984). "L`insertion de la sentence Dans l`ordre juridique francais", Le droit et la practique de l'arbitrage International en France, (Deduci,), pp. 81-84.

- Goldman, Berthold (1963). "Les conflits de loi dans l’arbitrage internacional de droit privé", Recueil des tours, Vol. 109, pp. 347 ss.

- Graham, James (2001). "La deslocalización del arbitraje virtual", Rev. De Derecho Informático, No40, nov. Disponible en: http://www. alfa-redi.org/rdi-articulo.shtml? $\mathrm{x}=879$

- Graham, James (2001a). "Grundlegung y lex contractus en los contratos estatales", Rev. Latinoamericana de Mediación y Arbitraje, No 18 .

- Grigera Naón, Horacio (2008), "El derecho aplicable en el arbitraje comercial internacional", en El contrato de arbitraje, Bogotá: Ed. Legis, pp. 607-617. 
- Hirsch, A. (1979). "The Place of Arbitration and the Lex Arbitri", The Arbitration Journal, sep. Vol. 34, no 3.

- Lavive, Pierre (1986). "Ordre public transnacional (ou réellement internacional) et arbitrage internacional", Rev. Arb., pp. 326-371.

- Mantilla-Serrano, Fernando (2009). "Algunos apuntes sobre la ejecución de los laudos anulados y la Convención de Nueva York", 15 INTERNATIONAL LAW, REV. COLOMBIANA DE DERECHO INTERNACIONAL, pp. $15-40$.

- Mereminskaya, E (2007), "Arbitraje comercial internacional", en Mario Ramírez Necochea: Análisis crítico del Derecho internacional privado chileno, LexisNexis.

- Oppetit, Bruno (1982). "La notion de source du droit el le droit du comerse internacional", Archives de philosophie du droit. No 27, "Sources" du droit, pp. 43-44.

- _ _ (2006). Teoría del arbitraje, (Traducido por Silva Romero, Eduardo / Mantilla Espinoza, Fabricio / Caicedo Demoulin, José), Bogotá, Ed. Legis, pp. 185-186.

- Paulsson, J. (1983). "Delocalization of International Commercial Arbitration: When and Why It Matters", International and Comparative Law Quarterly, No 33, pp. 53-61.

- Pérez Nieto, Leonel \& Graham, James (2006). "La muerte programada del Estado sede del arbitraje", Rev. Latinoamericana de Mediación y Arbitraje, № 2, México, pp. 197-208.

- Petsche, M. (2005). The growing Autonomy of International Commercial Arbitration, München: European Law Publishers

- Poudret, J. y Besson, S. (2007). Comparative Law of Internacional Arbitration, Londres, Sweet \& Maxwell.

- Rivera, Julio César, (2007), Arbitraje Comercial. Internacional y Doméstico, Lexisnexis, Bs. Aires.

- Santos Belandro, Rubén (2004). "Se ha instalado un provechoso quid quo en los Estados Latinoamericanos respecto del arbitraje", Rev. Vasca de Derecho Procesal y Arbitraje, tomo XVI, Bilbao, mayo, pp. 427-433.

- Vásquez palma, M. F. (2011), "Relevancia de la sede arbitral y criterios que determina su elección”, Revista Chilena de Derecho Privado, No16, pp. 75-134.

- Virgós Soriano, Miguel (2007), "Arbitraje comercial internacional y Convenio de Nueva York de 1958", en diario La Ley, año xxvii, No 6679, Madrid. 